Sādhanā Vol. 36, Part 2, April 2011, pp. 267-280. (C) Indian Academy of Sciences

\title{
Uncertainty modelling of critical column buckling for reinforced concrete buildings
}

\author{
KASIM A KORKMAZ*, FUAT DEMIR and HAMIDE TEKELI \\ Civil Engineering Department, Suleyman Demirel University, Isparta 32260, Turkey \\ e-mail: armagankorkmaz@sdu.edu.tr; fuatdemir@sdu.edu.tr; \\ hamidetekeli@sdu.edu.tr
}

MS received 26 January 2010; revised 15 December 2010; accepted 19 January 2011

\begin{abstract}
Buckling is a critical issue for structural stability in structural design. In most of the buckling analyses, applied loads, structural and material properties are considered certain. However, in reality, these parameters are uncertain. Therefore, a prognostic solution is necessary and uncertainties have to be considered. Fuzzy logic algorithms can be a solution to generate more dependable results. This study investigates the material uncertainties on column design and proposes an uncertainty model for critical column buckling reinforced concrete buildings. Fuzzy logic algorithm was employed in the study. Lower and upper bounds of elastic modulus representing material properties were defined to take uncertainties into account. The results show that uncertainties play an important role in stability analyses and should be considered in the design. The proposed approach is applicable to both future numerical and experimental researches. According to the study results, it is seen that, calculated buckling load values are stayed in lower and upper bounds while the load values are different for same concrete strength values by using different code formula.
\end{abstract}

Keywords. Uncertainty modelling; fuzzy system models; column buckling.

\section{Introduction}

Structural evaluation process consists of stability calculations, and checking buckling-limit load capacities of columns as structural elements. Stability calculations are critical in structural design can cause significant damage to structural column members (Faison et al 2004). The limit loads for columns, having major importance to a building's safety, are considered stability limits. Thus, a designer must evaluate the critical load limits. Among the main design codes, essential limitations are defined (UBC 1997; TDC 2007). In most of the buckling analyses, applied loads, structural and material properties are considered certain.

In reality, some of the design parameters in structural analysis may be disregarded which can lead to uncertainties. Uncertainties in the input should be considered and output uncertainties

*For correspondence 
should be mirrored in structural response variables. The input information can be generally classified into load, material and structural uncertainties. Material properties in structural evaluation and design are critical for the stability. Material properties affect the critical value of the buckling loads. Concrete strength is counted as one of the important parameters for the material properties in reinforced concrete structure design. Reinforced concrete materials contain uncertainties causing the scatter of its mechanical properties and durability. Therefore, a prognostic solution is necessary and uncertainties have to be considered. Different approaches are available for considering the uncertainty. Uncertainty assessments may be subdivided into four groups: probability theory, fuzzy theory, convex models, and interval calculations. Fuzzy theory could be one of the practical solutions.

Various research works have been carried out for uncertainty analysis in structural design (Biondini et al 2004; Moller \& Beer 2004; Moller et al 2003; Kim et al 2006; Noor et al 2001; Ben-Haim \& Elishakoff 1990; Elishakoff 1999; Pantelides \& Booth 1999; Akkurt et al 2003). For reasonable computer expenses, only the most important variables should be treated statistically. On the other hand, the set of selected random variables reflect all principal sources of uncertainty for realistic response predictions (Pucklicky \& Kala 2009; Petryna \& Kratzig 2005; Petryna et al 2002).

In this study, a new approach is proposed to investigate the effects of material uncertainty of concrete on calculating critical buckling loads of reinforced concrete column members. An uncertainty modelling framework for reinforced concrete buildings were established, which balances the accuracy of the structural models by using experimental results and design codes (Baalbaki et al 1991; Gesoglu et al 2002; Ke-Ru et al 2001; Shannag 2002; Wee et al 1994; ACI 1996; GBJ11 1994; CEB-FIB 1993; NS 1992; TS500 2000; IDC 2003; GDC 2000). Predicted upper and lower bounds of elastic moduli using fuzzy logic algorithm were used to consider the material uncertainty for determining buckling load. By defining lower and upper bounds of elastic moduli, this study provides a spectrum for reinforced concrete column members. For comparison and evaluation of the effects of the material properties on buckling limit loads, twodimension and three-dimension design buildings from open literature were analysed (Girgin et al 2006; Girgin \& Ozmen 2007). The present study is based on related research works (Demir \& Korkmaz 2008; Demir 2005; Korkmaz et al 2008; 2009) and fuzzy logic algorithm was used for determining buckling loads for reinforced concrete columns.

\section{Evaluation and classification of material uncertainties}

Structural assessments need appropriate material models, advanced structural simulation tools and probabilistic approaches to consider unavoidable uncertainties. Due to the complexity of the engineering problems, analysis has been typically carried out only for specific problems, in which some aspects are considered very accurately, whereas others are often oversimplified.

The material modelling of reinforced concrete consisting generally of three phases: cement mortar, aggregate grains and reinforcing steel bars, is a strong compromise between the structural phenomena and available material parameters. In structural analysis, reinforced concrete materials are modelled as a macroscopically homogeneous material with response influences by each of the phases. On the other hand, it is known that, one of the important parameters of concrete material is compressive strength. Many parameters affect the concrete strength. It can be assumed that there are also many uncertainties relevant to the concrete material definition. Material properties can be defined through concrete strength and modulus of elasticity as proposed in different national building codes through various formulas for the same values of concrete strength. In the 
present study, selected seven different design codes were considered in the analyses. Considered design codes were published by American Concrete Institute (ACI), Chinese Design Council (GBJ), Euro-International Concrete Committee (CEB), Norwegian Council for Building Standardization (NS), Turkish Standard Committee (TS), Italian (IDC) and Greek (GDC) Design Councils. The design codes propose different elastic moduli formulae are given below.

$\begin{array}{lc}\text { ACI 318-95 } & \mathrm{E}_{\mathrm{c}}=4.73\left(\mathrm{f}_{\mathrm{c}}\right)^{1 / 2}, \\ \text { GBJ 11-89 } & \mathrm{E}_{\mathrm{c}}=10^{2} /\left[2.2+\left(34.7 / \mathrm{f}_{\mathrm{c}}\right)\right], \\ \text { CEB 90 } & \mathrm{E}_{\mathrm{c}}=10\left(\mathrm{f}_{\mathrm{c}}+8\right)^{1 / 3}, \\ \text { NS 3473 } & \mathrm{E}_{\mathrm{c}}=9.5\left(\mathrm{f}_{\mathrm{c}}\right)^{0,3}, \\ \text { TS 500 } & \mathrm{E}_{\mathrm{c}}=3.25\left(\mathrm{f}_{\mathrm{c}}\right)^{1 / 2}+14, \\ \text { IDC 3274 } & \mathrm{E}_{\mathrm{c}}=5.7\left(\mathrm{f}_{\mathrm{c}}\right)^{1 / 2}, \\ \text { GDC 2000 } & \mathrm{E}_{\mathrm{c}}=4.76\left(\mathrm{f}_{\mathrm{c}}\right)^{1 / 2} .\end{array}$

Relationships $\mathrm{f}_{\mathrm{c}}$ and $\mathrm{E}_{\mathrm{c}}$ are expressed in $\mathrm{MPa}$ and in GPa, respectively.

\section{Fuzzy logic algorithm}

The fuzzy logic concept provides a natural way of dealing with problems in which the source of imprecision is an absence of sharply defined criteria rather than the presence of random variables. The fuzzy approach considers cases where uncertainties play a role in the control mechanism of the concerned phenomena. Fuzzy propositions (i.e., IF-THEN statements) are used to characterize the state of a system and the true value of the proposition which is a measure of how well the description matches the state of the system. The key idea in fuzzy logic is the allowance of the partial belonging of any object to different subsets of the universal set instead of belonging completely to a single set. Partial belonging to a set can be described numerically by a membership function (MF) which assumes values between 0 and 1 inclusively. Even if the measurements are carefully completed as crisp quantities, they can be fuzzified. Furthermore, if the form of uncertainty arises because of imprecision, then the variable is fuzzy and can be represented by a MF (Demir \& Korkmaz 2008; Demir 2005; Korkmaz et al 2008; 2009). In the present study, based on the previous research works (Demir \& Korkmaz 2008; Demir 2005; Korkmaz et al 2008; 2009) fuzzy logic algorithm was carried out to define elastic moduli for uncertainty modelling in calculation of column buckling load as defined in the following section.

\section{Fuzzy logic algorithm for uncertainty modelling}

The fuzzy logic algorithm, which allows more dependable results in engineering problems, has an application for uncertainty modelling. For years, the fuzzy logic algorithm, attested by many researchers to application in structural engineering, has been successfully applied to different 


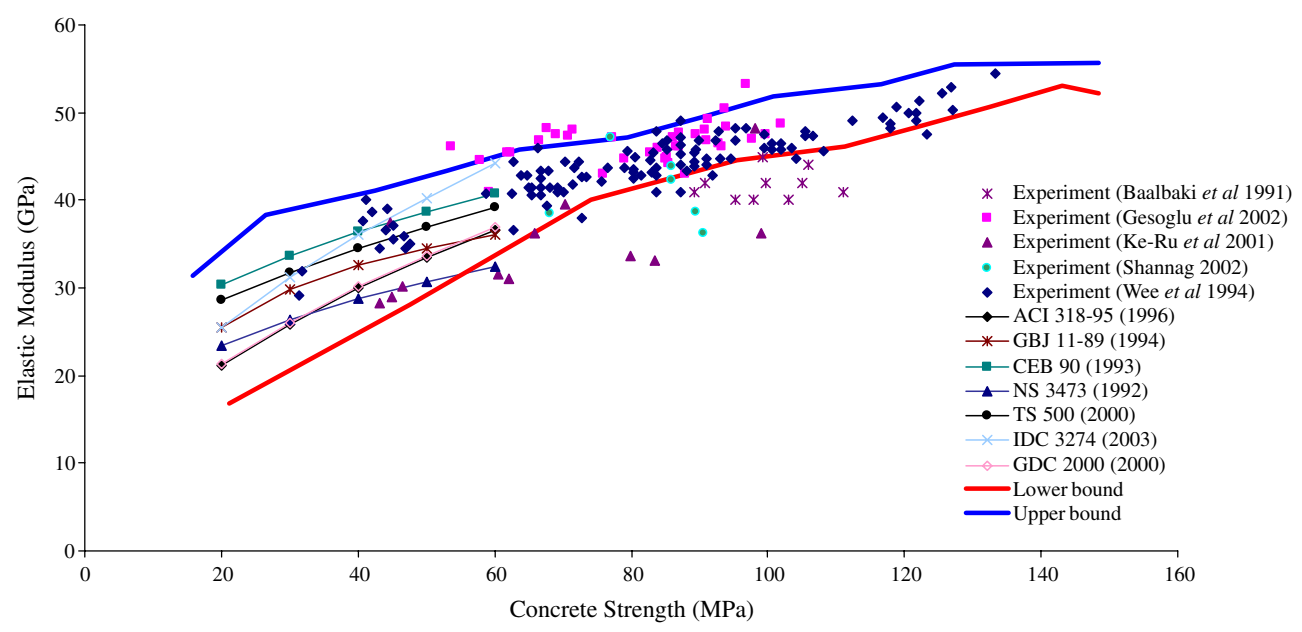

Figure 1. Material properties as a function of the compressive strength.

areas in engineering such as structural design, modelling and many more. Fuzzy logic techniques have been applied to simulate uncertainties involved in engineering operations.

Material uncertainty can be defined by using main important parameters which are concrete compressive strength and elastic modulus. Elastic modulus for normal strength of concrete is defined as a function of the different design codes appear in figure 1 (Demir \& Korkmaz 2008). As it can be seen in figure 1, when the concrete strength is approximately $40 \mathrm{MPa}$, modulus of elasticity varies between approximately 30 and $40 \mathrm{GPa}$. Therefore, using a given value can mislead the analysis results. Determining upper and lower bounds for material properties to consider material uncertainty, using the value becomes a critical solution and is a more accurate and safe method compared to using a given values. The compression strength and modulus of elasticity fuzzy subsets: $\mathrm{C}_{1}, \mathrm{C}_{2}, \mathrm{C}_{3}, \ldots, \mathrm{C}_{13}$ and $\mathrm{E}_{\mathrm{c} 1}, \mathrm{E}_{\mathrm{c} 2}, \mathrm{E}_{\mathrm{c} 3}, \ldots, \mathrm{E}_{\mathrm{c} 13}$, respectively were considered to have triangular membership functions represented in figures 2 and 3, respectively (Demir \& Korkmaz 2008; Kosko 1992). Based on the experimental studies, elastic moduli values were determined according to different concrete strength. For instance, for range of $\mathrm{C}_{1}$ concrete strength, $\mathrm{E}_{1}$ can be used as shown in figures 2 and 3 . Rules are based on 'if the concrete strength range $C_{i}+C_{i+1}$ then, Elastic moduli range $\mathrm{E}_{\mathrm{i}}+\mathrm{E}_{\mathrm{i}+1}(\mathrm{i}=1,2,3, \ldots 11)$ '.

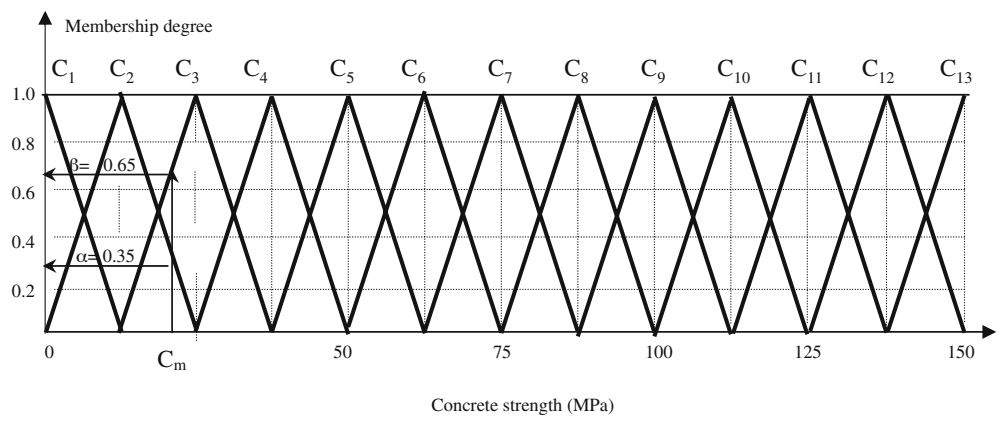

Figure 2. Fuzzy subset membership functions for compressive strength class. 


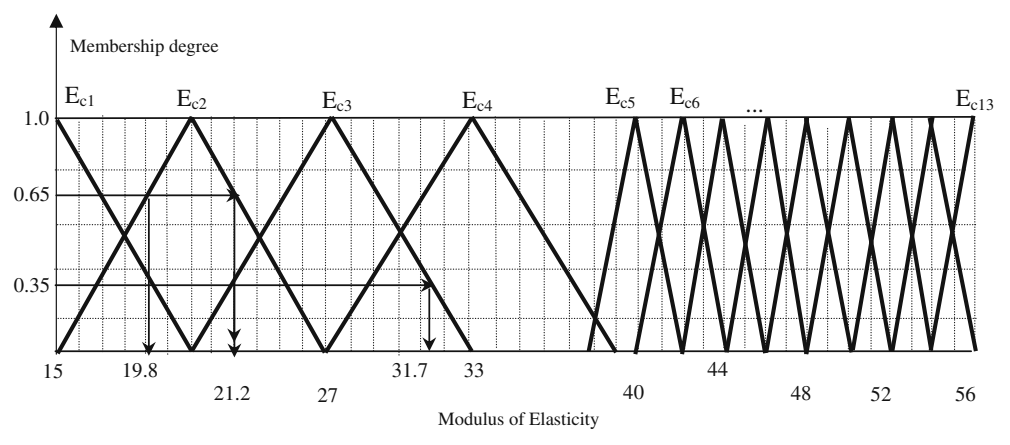

Figure 3. Fuzzy subset membership functions for material property.

Material properties may lead to variation in buckling loads. A more accurate material property definition cause more reliable critical buckling load calculations. In structural design, buckling as one of the measurements of stability can affect the design of structural elements. In general, determination of the values of 'buckling load limitation' is based on general consideration from the designer's experiences and the measured values of the project.

A reinforced concrete column is simply a common case of a compression member. With any vertical load, the column should remain straight and be supported. In engineering problems, buckling is a failure mode characterized by a sudden failure of a structural member subjected to high compressive stresses, where the actual compressive stresses at failure are smaller than the ultimate compressive stresses that the material is capable of withstanding. Buckling failure is also described as failure due to elastic instability. Mathematical analysis of buckling brings an axial load eccentricity that causes a moment, which does not form part of the primary forces to which the member is subjected (Girgin \& Ozmen 2007).

\section{Effects of material uncertainty on critical buckling load}

There are various research works available in the literature for determining buckling loads. In this study, simplified procedure for determining buckling loads given by Girgin \& Ozmen (2007) was taken into account to investigate the effect of material uncertainty.

Cakiroglu (1962) and Stevens (1967) developed the earliest methods for determining approximate values for the buckling load of buildings. Girgin \& Ozmen (2007) proposed a simplified procedure for determining buckling loads of three-dimensional framed buildings. For the storybuckling approach, the studies of Lui (1992), Aristizabal-Ochoa (1997) and Cheong-Siat-Moy (1999) were highlighted in the literature for such a consideration. Another method for unbraced regular buildings, 'the story buckling approach' which accounts for the horizontal interaction between columns was developed by Yura (1971) and LeMessurier (1977). A reasonably comprehensive documentary of buckling studies is given by Ozmen \& Girgin (2005). The other relevant researches were carried out by Mata et al (2008), Battini \& Pacoste (2002) and Bratina et al (2004).

The Euler formula given in Eq. 8, describes the critical buckling load for elastic buckling and is valid only for long columns. The ultimate compression strength of the column material is not geometry-related and is valid only for short columns. In between, for a column with intermediate length, buckling occurs after the stress in the column exceeds the proportional limit of the column 
material and before the stress reaches the ultimate strength. This is called as inelastic buckling (Girgin et al 2006; Girgin and Ozmen 2007). Euler investigated that, there was a critical load for buckling of a column. Euler's formula is

$$
\mathrm{P}_{\mathrm{cr}}=\frac{\mathrm{EI} \pi^{2}}{(\mathrm{k} \times \mathrm{L})^{2}}
$$

where $\mathrm{E}$ is the modulus of elasticity of the column member representing the material property, I is the area moment of inertia of the cross-section, $\mathrm{k}$ is the column effective length factor, whose value depends on the conditions of end support of the column and $\mathrm{L}$ is the length of the column.

As given in Eq. 8., critical buckling load directly relates to material properties. Therefore, differences in material properties cause differences in calculation of critical buckling load. For instance, from experimental studies, when the concrete strength is $42.7 \mathrm{MPa}$, modulus of elasticity is $37.6 \mathrm{GPa}$ (Ke-Ru et al 2001). By using the fuzzy logic algorithm, modulus of elasticity is determined as $30.5 \mathrm{GPa}$ and $40.2 \mathrm{GPa}$ corresponding upper and lower bounds respectively (Demir \& Korkmaz 2008; Demir 2005; Korkmaz et al 2008, 2009). In table 1, material properties according to different design codes are given.

Column internal forces consist axial forces $\mathrm{N}$ while all the internal forces of the beams are zero. The axial force of a column may be expressed as (Girgin \& Ozmen 2007).

$$
\mathrm{N}=\mathrm{n} \times \mathrm{P}
$$

where $\mathrm{n}$ is a dimensionless coefficient and $\mathrm{P}$ is an arbitrarily chosen load parameter.

The buckling load is obtained from Eq. (10), where $\mathrm{P}_{\mathrm{cr}}$ is buckling load; $\mathrm{H}_{\mathrm{x}}, \mathrm{H}_{\mathrm{y}}$ are lateral story loads; $\mathrm{d}_{\mathrm{x}}, \mathrm{d}_{\mathrm{y}}$ are story displacements; $\mathrm{n}$ is a dimensionless coefficient; $\mathrm{h}_{\mathrm{c}}$ is height of a particular column, and $\delta_{\mathrm{x}}, \delta_{\mathrm{y}}$ are relative displacements (Girgin \& Ozmen 2007):

$$
\mathrm{P}_{\mathrm{cr}}=\frac{\sum_{\text {joints }} \mathrm{H}_{\mathrm{x}} \mathrm{d}_{\mathrm{x}}+\mathrm{H}_{\mathrm{y}} \mathrm{d}_{\mathrm{y}}}{1.2 \sum_{\text {columns }} \mathrm{C}^{\mathrm{a}}}
$$

Table 1. Elastic modulus values for a given concrete strength $\left(\mathrm{f}_{\mathrm{c}}=42.7 \mathrm{MPa}\right)$.

\begin{tabular}{lc}
\hline References & Modulus of elasticity (GPa) \\
\hline Experiment (Ke-Ru et al 2001) & 37.60 \\
ACI 318-95 (1996) & 30.90 \\
GBJ 11-89 (1994) & 33.19 \\
CEB 90 (1993) & 37.01 \\
NS 3473 (1992) & 30.80 \\
TS 500 (2000) & 35.24 \\
IDC 3274 (2003) & 37.25 \\
GDC 2000 (2000) & 31.10 \\
Lower bound & 30.50 \\
Upper bound & 40.20 \\
\hline
\end{tabular}




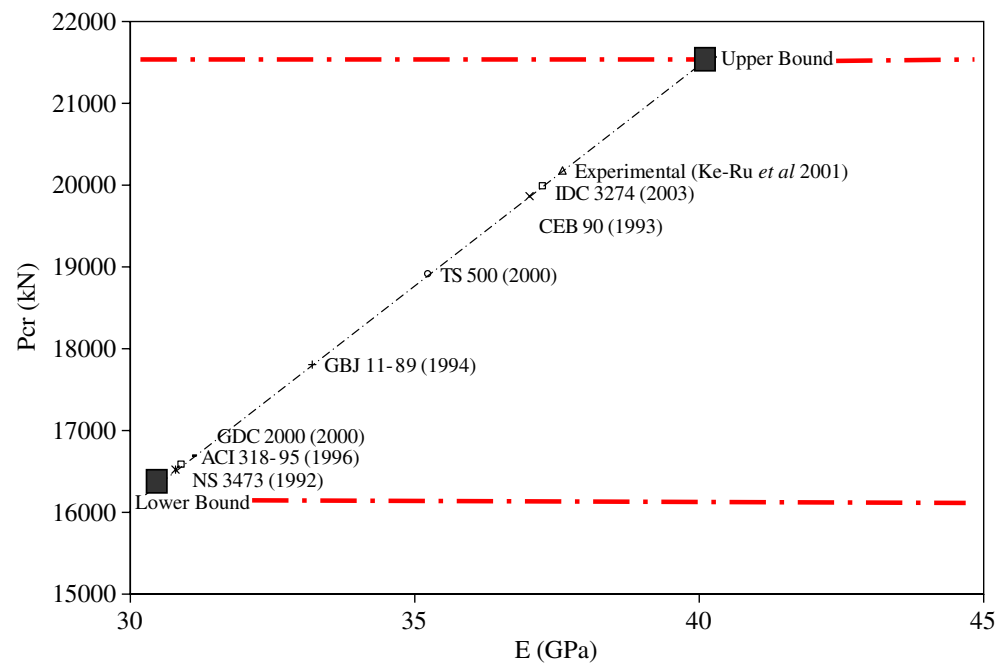

Figure 4. Material property change with critical buckling load according to different codes and experiment.

where $\mathrm{C}^{\mathrm{a}}$ can be calculated as given in Eq. (11).

$$
\mathrm{C}^{\mathrm{a}}=\frac{\mathrm{n}}{\mathrm{h}_{\mathrm{c}}}\left(\delta_{\mathrm{x}}^{2}+\delta_{\mathrm{y}}^{2}\right)
$$

The formula for $\mathrm{P}_{\mathrm{cr}}$ is an approximate one, since the fictitious lateral loading corresponding to the buckling mode displacements are not known initially. As shown in figure 4, the result is a straight line, on which all data points lie and all data are in between lower and upper bounds. Applications of several calculations have shown that the value of $\mathrm{P}_{\mathrm{cr}}$ is not strongly dependent on the initial choice of lateral loads. The recommendation may be that the lateral load at each

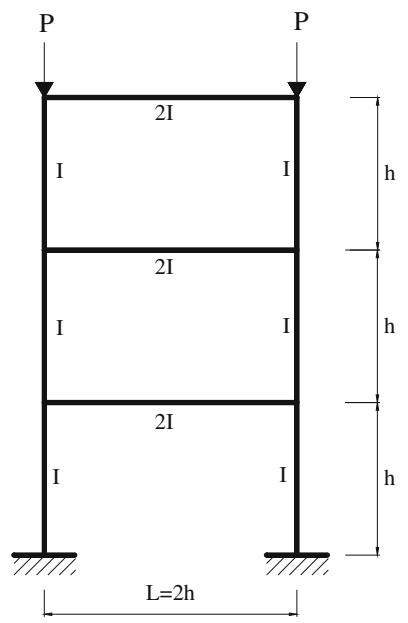

Figure 5. Dimensions and loading of 2D building (Girgin et al 2006). 
Table 2. Buckling loads for $2 \mathrm{D}$ building calculated with elastic moduli obtained from different design codes and experiment.

\begin{tabular}{lc}
\hline Design codes & Pcr $(\mathrm{kN})$ \\
\hline Experiment (Ke-Ru et al 2001) & 161.7 \\
ACI 318-95 (1996) & 132.9 \\
GBJ 11-89 (1994) & 142.8 \\
CEB 90 (1993) & 159.2 \\
NS 3473 (1992) & 132.5 \\
TS 500 (2000) & 151.6 \\
IDC 3274 (2003) & 160.2 \\
GDC 2000 (2000) & 133.8 \\
Lower bound & 131.2 \\
Upper bound & 172.9 \\
\hline
\end{tabular}

joint should be selected as proportional to the vertical load, $P_{i}$, existing at the joint (Girgin \& Ozmen 2007). Displacement values are changed due to different modulus of elasticity values. Therefore, uncertainties are taken into account by using different displacement values.

To demonstrate the importance of material properties, existing 2D and 3D buildings were selected from the open literature (Girgin et al 2006; Girgin \& Ozmen 2007). Different material properties were defined to calculate the critical buckling loads.

The dimensions and loading of a regular three-story 2D building are shown in the schematic elevation in figure 5 and buckling load can be determined by using Eq. (12) (Girgin et al 2006).

$$
\mathrm{P}_{\mathrm{cr}}=4.301 \times \frac{\mathrm{EI}}{\mathrm{h}^{2}} \text {. }
$$

Through variety in the material properties, buckling load values were calculated for the $2 \mathrm{D}$ building as given in table 2. Figure 6 depicts calculated buckling load values according to different design codes, experimental results and upper and lower bounds for three-story 2D building.

In figure 7, dimensions and loading of a regular two-story 3D building are given. The beams at the lower right corner of the $1^{\text {st }}$ story are curtailed, making building irregular, i.e., the story buckling approaches are not applicable. However, apparently that the proposed method can be applied to these kind of buildings as readily. The floors consist of $120 \mathrm{~mm}$ thick plates, which act as rigid diaphragms. Beam and column cross sections are $250 \times 500 \mathrm{~mm}$ and $350 \times 350 \mathrm{~mm}$, respectively (Girgin \& Ozmen 2007).

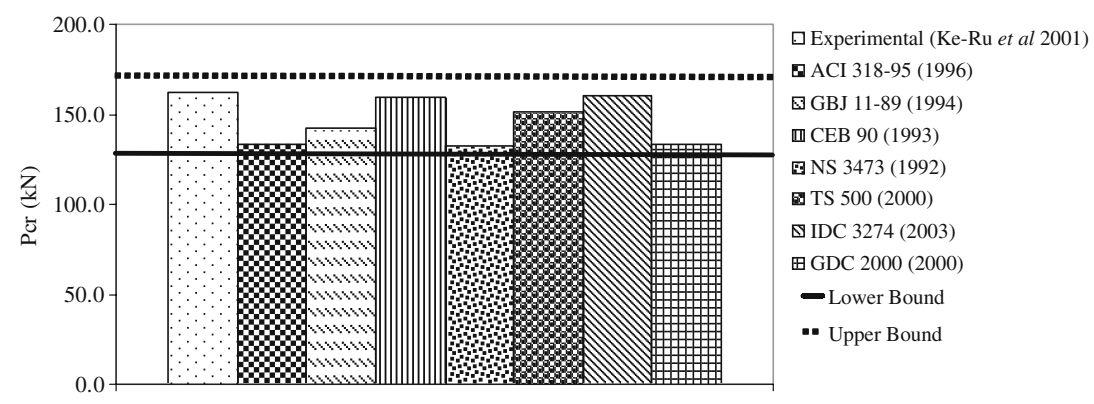

Figure 6. Bucking loads for $2 \mathrm{D}$ building calculated according to different design codes and experiment. 


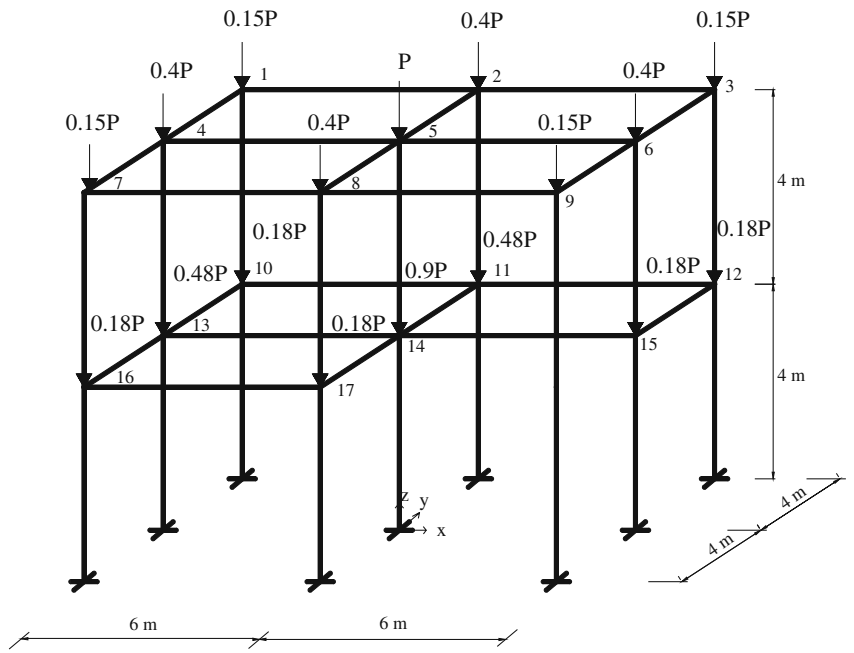

Figure 7. Dimensions and loading of 3D building (Girgin \& Ozmen 2007).

Table 3. Bucking load for 3D building calculated with experimental elastic modulus value (Ke-Ru et al 2001).

\begin{tabular}{|c|c|c|c|c|c|c|c|c|c|}
\hline $\begin{array}{l}\text { Joint } \\
\text { (column) } \\
\text { no. }\end{array}$ & $\begin{array}{l}\mathrm{H}_{\mathrm{x}} \\
(\mathrm{kN})\end{array}$ & $\mathrm{d}_{\mathrm{x}} \times 10^{5} \mathrm{~m}$ & $\mathrm{~d}_{\mathrm{y}} \times 10^{5} \mathrm{~m}$ & $\mathrm{H}_{\mathrm{x}} \times \mathrm{d}_{\mathrm{x}}$ & $\delta_{\mathrm{x}} \times 10^{5} \mathrm{~m}$ & $\delta_{\mathrm{y}} \times 10^{5} \mathrm{~m}$ & $\mathrm{n}$ & $\begin{array}{l}\mathrm{h}_{\mathrm{c}} \\
(\mathrm{m})\end{array}$ & $\mathrm{C}^{\mathrm{a}}$ \\
\hline 1 & 0.15 & 31.40 & -0.59 & 4.71 & 14.05 & -0.38 & 0.15 & 4.00 & 7.41 \\
\hline 2 & 0.40 & 31.40 & 0.00 & 12.56 & 14.05 & 0.00 & 0.40 & 4.00 & 19.74 \\
\hline 3 & 0.15 & 31.40 & 0.68 & 4.71 & 14.05 & 0.45 & 0.15 & 4.00 & 7.41 \\
\hline 4 & 0.40 & 31.83 & -0.59 & 12.73 & 14.33 & -0.38 & 0.40 & 4.00 & 20.55 \\
\hline 5 & 1.00 & 31.83 & 0.00 & 31.83 & 14.33 & 0.00 & 1.00 & 4.00 & 51.34 \\
\hline 6 & 0.40 & 31.83 & 0.68 & 12.73 & 14.33 & 0.45 & 0.40 & 4.00 & 20.55 \\
\hline 7 & 0.15 & 32.25 & -0.59 & 4.84 & 14.60 & -0.38 & 0.15 & 4.00 & 8.00 \\
\hline 8 & 0.40 & 32.25 & 0.00 & 12.90 & 14.60 & 0.00 & 0.40 & 4.00 & 21.32 \\
\hline 9 & 0.15 & 32.25 & 0.68 & 4.84 & 32.25 & 0.68 & 0.15 & 8.00 & 19.51 \\
\hline 10 & 0.18 & 17.35 & -0.21 & 3.12 & 17.35 & -0.21 & 0.33 & 4.00 & 24.85 \\
\hline 11 & 0.48 & 17.35 & 0.00 & 8.33 & 17.35 & 0.00 & 0.88 & 4.00 & 66.25 \\
\hline 12 & 0.18 & 17.35 & 0.23 & 3.12 & 17.35 & 0.23 & 0.33 & 4.00 & 24.85 \\
\hline 13 & 0.48 & 17.50 & -0.21 & 8.40 & 17.50 & -0.21 & 0.88 & 4.00 & 67.36 \\
\hline 14 & 0.90 & 17.50 & 0.00 & 15.75 & 17.50 & 0.00 & 1.90 & 4.00 & 145.42 \\
\hline 15 & 0.18 & 17.50 & 0.23 & 3.15 & 17.50 & 0.23 & 0.58 & 4.00 & 44.40 \\
\hline 16 & 0.18 & 17.65 & -0.21 & 3.18 & 17.65 & -0.21 & 0.33 & 4.00 & 25.70 \\
\hline 17 & 0.18 & 17.65 & 0.00 & 3.18 & 17.65 & 0.00 & 0.58 & 4.00 & 45.17 \\
\hline Sum & & & & 150.07 & & & & & 619.84 \\
\hline
\end{tabular}

Buckling load $P_{c r}=\frac{150.07 \times 10^{-5}}{1.2 \times 619.84 \times 10^{-10}}=20176.5 \mathrm{kN}$ 
Table 4. Bucking load for 3D building calculated with lower bound elastic modulus value.

\begin{tabular}{|c|c|c|c|c|c|c|c|c|c|}
\hline $\begin{array}{l}\text { Joint } \\
\text { (column) no. }\end{array}$ & $\begin{array}{c}\mathrm{H}_{\mathrm{x}} \\
(\mathrm{kN})\end{array}$ & $\mathrm{d}_{\mathrm{x}} \times 10^{5} \mathrm{~m}$ & $\mathrm{~d}_{\mathrm{y}} \times 10^{5} \mathrm{~m}$ & $\mathrm{H}_{\mathrm{x}} \times \mathrm{d}_{\mathrm{x}}$ & $\delta_{\mathrm{x}} \times 10^{5} \mathrm{~m}$ & $\delta_{\mathrm{y}} \times 10^{5} \mathrm{~m}$ & $\mathrm{n}$ & $\begin{array}{l}\mathrm{h}_{\mathrm{c}} \\
(\mathrm{m})\end{array}$ & $\mathrm{C}^{a}$ \\
\hline 1 & 0.15 & 38.71 & -0.73 & 5.81 & 17.32 & -0.47 & 0.15 & 4.00 & 11.26 \\
\hline 2 & 0.40 & 38.71 & 0.00 & 15.49 & 17.32 & 0.00 & 0.40 & 4.00 & 30.00 \\
\hline 3 & 0.15 & 38.71 & 0.84 & 5.81 & 17.32 & 0.55 & 0.15 & 4.00 & 11.26 \\
\hline 4 & 0.40 & 39.24 & -0.73 & 15.69 & 17.67 & -0.47 & 0.40 & 4.00 & 31.23 \\
\hline 5 & 1.00 & 39.24 & 0.00 & 39.24 & 17.67 & 0.00 & 1.00 & 4.00 & 78.02 \\
\hline 6 & 0.40 & 39.24 & 0.84 & 15.69 & 17.67 & 0.55 & 0.40 & 4.00 & 31.24 \\
\hline 7 & 0.15 & 39.76 & -0.73 & 5.96 & 18.00 & -0.47 & 0.15 & 4.00 & 12.16 \\
\hline 8 & 0.40 & 39.76 & 0.00 & 15.90 & 18.00 & 0.00 & 0.40 & 4.00 & 32.40 \\
\hline 9 & 0.15 & 39.76 & 0.84 & 5.96 & 39.76 & 0.84 & 0.15 & 8.00 & 29.65 \\
\hline 10 & 0.18 & 21.39 & -0.26 & 3.85 & 21.39 & -0.26 & 0.33 & 4.00 & 37.76 \\
\hline 11 & 0.48 & 21.39 & 0.00 & 10.27 & 21.39 & 0.00 & 0.88 & 4.00 & 100.69 \\
\hline 12 & 0.18 & 21.39 & 0.29 & 3.85 & 21.39 & 0.29 & 0.33 & 4.00 & 37.77 \\
\hline 13 & 0.48 & 21.57 & -0.26 & 10.35 & 21.57 & -0.26 & 0.88 & 4.00 & 102.38 \\
\hline 14 & 0.90 & 21.57 & 0.00 & 19.41 & 21.57 & 0.00 & 1.90 & 4.00 & 221.01 \\
\hline 15 & 0.18 & 21.57 & 0.29 & 3.88 & 21.57 & 0.29 & 0.58 & 4.00 & 67.48 \\
\hline 16 & 0.18 & 21.76 & -0.26 & 3.92 & 21.76 & -0.26 & 0.33 & 4.00 & 39.06 \\
\hline 17 & 0.18 & 21.76 & 0.00 & 3.92 & 21.76 & 0.00 & 0.58 & 4.00 & 68.64 \\
\hline Sum & & & & 185.01 & & & & & 942.00 \\
\hline \multicolumn{10}{|c|}{$\frac{185.01 \times 10^{-5}}{10}=16367 \mathrm{kN}$} \\
\hline
\end{tabular}

Table 5. Bucking load for 3D building calculated with upper bound elastic modulus value.

\begin{tabular}{|c|c|c|c|c|c|c|c|c|c|}
\hline $\begin{array}{l}\text { Joint } \\
\text { (column)no. }\end{array}$ & $\begin{array}{l}\mathrm{H}_{\mathrm{x}} \\
(\mathrm{kN})\end{array}$ & $\mathrm{d}_{\mathrm{x}} \times 10^{5} \mathrm{~m}$ & $\mathrm{~d}_{\mathrm{y}} \times 10^{5} \mathrm{~m}$ & $\mathrm{H}_{\mathrm{x}} \times \mathrm{d}_{\mathrm{x}}$ & $\delta_{\mathrm{x}} \times 10^{5} \mathrm{~m}$ & $\delta_{\mathrm{y}} \times 10^{5} \mathrm{~m}$ & $\mathrm{n}$ & $\begin{array}{l}\mathrm{h}_{\mathrm{c}} \\
(\mathrm{m})\end{array}$ & $\mathrm{C}^{\mathrm{a}}$ \\
\hline 1 & 0.15 & 29.37 & -0.55 & 4.41 & 13.14 & -0.36 & 0.15 & 4.00 & 6.48 \\
\hline 2 & 0.40 & 29.37 & 0.00 & 11.75 & 13.14 & 0.00 & 0.40 & 4.00 & 17.27 \\
\hline 3 & 0.15 & 29.37 & 0.63 & 4.41 & 13.14 & 0.42 & 0.15 & 4.00 & 6.48 \\
\hline 4 & 0.40 & 29.77 & -0.55 & 11.91 & 13.40 & -0.36 & 0.40 & 4.00 & 17.98 \\
\hline 5 & 1.00 & 29.77 & 0.00 & 29.77 & 13.40 & 0.00 & 1.00 & 4.00 & 44.91 \\
\hline 6 & 0.40 & 29.77 & 0.63 & 11.91 & 13.40 & 0.42 & 0.40 & 4.00 & 17.98 \\
\hline 7 & 0.15 & 30.16 & -0.55 & 4.52 & 13.66 & -0.36 & 0.15 & 4.00 & 7.00 \\
\hline 8 & 0.40 & 30.16 & 0.00 & 12.07 & 13.66 & 0.00 & 0.40 & 4.00 & 18.65 \\
\hline 9 & 0.15 & 30.16 & 0.63 & 4.52 & 30.16 & 0.63 & 0.15 & 8.00 & 17.07 \\
\hline 10 & 0.18 & 16.23 & -0.19 & 2.92 & 16.23 & -0.19 & 0.33 & 4.00 & 21.74 \\
\hline 11 & 0.48 & 16.23 & 0.00 & 7.79 & 16.23 & 0.00 & 0.88 & 4.00 & 57.96 \\
\hline 12 & 0.18 & 16.23 & 0.22 & 2.92 & 16.23 & 0.22 & 0.33 & 4.00 & 21.74 \\
\hline 13 & 0.48 & 16.37 & -0.19 & 7.86 & 16.37 & -0.19 & 0.88 & 4.00 & 58.93 \\
\hline 14 & 0.90 & 16.37 & 0.00 & 14.73 & 16.37 & 0.00 & 1.90 & 4.00 & 127.22 \\
\hline 15 & 0.18 & 16.37 & 0.22 & 2.95 & 16.37 & 0.22 & 0.58 & 4.00 & 38.84 \\
\hline 16 & 0.18 & 16.51 & -0.19 & 2.97 & 16.51 & -0.19 & 0.33 & 4.00 & 22.48 \\
\hline 17 & 0.18 & 16.51 & 0.00 & 2.97 & 16.51 & 0.00 & 0.58 & 4.00 & 39.51 \\
\hline Sum & & & & 140.37 & & & & & 542.25 \\
\hline \multicolumn{10}{|c|}{$\frac{140.37 \times 10^{-5}}{2 \times 542.25 \times 10^{-10}}=21572 \mathrm{kN}$} \\
\hline
\end{tabular}


Table 6. Buckling loads for 3D building calculated with elastic moduli obtained from different design codes and experiment.

\begin{tabular}{lc}
\hline Design codes & $\mathrm{P}_{\mathrm{cr}}(\mathrm{kN})$ \\
\hline Experiment $(\mathrm{Ke}-\mathrm{Ru}$ et al 2001) & 20177 \\
ACI 318-95 (1996) & 16581 \\
GBJ 11-89 (1994) & 17810 \\
CEB 90 (1993) & 19860 \\
NS 3473 (1992) & 16528 \\
TS 500 (2000) & 18910 \\
IDC 3274 (2003) & 19989 \\
GDC 2000 (2000) & 16689 \\
Lower bound & 16367 \\
Upper bound & 21572 \\
\hline
\end{tabular}

Elastic moduli calculated for different codes and obtained from experiment were given in table 1. Calculated buckling load values are given in the table 2 for $2 \mathrm{D}$ building. Tables 3,4 and 5 demonstrate calculated buckling load values with experimental, lower and upper elastic moduli values for 3D building respectively. All calculated buckling load values with elastic moduli obtained from different design codes and experiment for 3D building are summarized in table 6. Figure 8 depicts buckling load values calculated according to the different design codes, experimental results and upper and lower values for two-story 3D building.

As shown in table 2, for the 2D building, critical buckling load is determined as $161.7 \mathrm{kN}$ for 42.7 MPa concrete strength according Ke-Ru et al (2001). Critical buckling loads for the same concrete strength were calculated between $132.5 \mathrm{kN}$ and $160.2 \mathrm{kN}$ according to different design codes. Lower and upper bounds of critical buckling load values were determined as $131.2 \mathrm{kN}$ and $172.9 \mathrm{kN}$ respectively which cover values determined by all given design codes and experimental study. For the 3D building, the same results were found as indicated in table 6 . The proposed approach covers different code values and gives more reliable results.

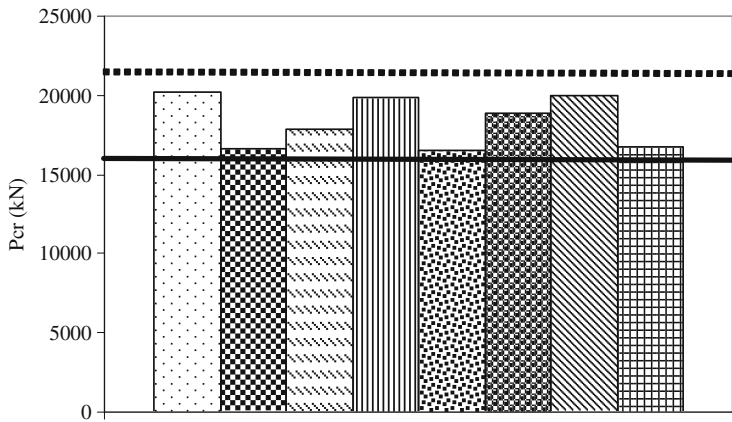

$\square$ Experimental (Ke-Ru et al 2001)

ACI 318-95 (1996)

曰GBJ 11-89 (1994)

m CEB 90 (1993)

원 NS 3473 (1992)

먼 $500(2000)$

⿶ IDC 3274 (2003)

$\boxplus$ GDC 2000 (2000)

- Lower Bound

-. Upper Bound

Figure 8. Buckling loads for 3D building calculated according to different design codes and experiment. 


\section{Conclusion}

In this study, the effect of material uncertainty on the buckling of reinforced concrete columns was investigated. Material uncertainty was represented by the main important parameters of concrete as concrete strength and elastic moduli. Uncertainty in material was considered as the lower and upper bounds of elastic moduli for defined concrete strength, determined by various design codes. The proposed methodology was established by using fuzzy logic algorithm to cover varying design values arising from differences in calculation methods. The adaptation of the proposed fuzzy subsets and rule bases are straightforward for any elastic modulus and compressive strength. The fuzzy logic concept provides a practical approach of dealing with problems in which the source of imprecision is an absence of sharply defined criteria rather than the presence of random variables.

By defining lower and upper bounds of the material properties, this study gives a spectrum that covers different codified values. Providing a range for material property is a more reliable approach in structural design calculations. This study also investigated the effects of the prediction of the bounds of the material properties on buckling limit loads. Critical buckling load is among the important structural stability criteria directly related to the material properties. A more accurate material property definition creates more reliable critical buckling load calculations.

Buckling load values calculated according to the different design codes, experimental results and upper and lower values for $2 \mathrm{D}$ and $3 \mathrm{D}$ buildings were compared. It is seen that the results are consistent and all code results are in between lower and upper bounds.

\section{References}

ACI 318-95 1996 Building code requirements for structural concrete, ACI Manual of Concrete Practice Part 3: Use of concrete in Buildings Design, Specifications, and Related Topics Detroit, Michigan

Akkurt S, Ozdemir S, Tayfur G, Akyol B 2003 The use of GA-ANNs in the modelling of compressive strength of cement mortar. Cement and Concrete Research 33: 973-979

Aristizabal-Ochoa J D 1997 Braced, partially braced and unbraced frames: Classical approach. J. Struct. Eng. 123(6): 799-807

Baalbaki W, Benmokrane B, Chaallal O, Aitcin PC 1991 Influence of coarse aggregate on elastic properties on high performance concrete. ACI Materials Journal 88(5): 499-503

Battini M, Pacoste C 2002 Co-rotational beam elements with warping effects in instability problems. Comput. Methods Applied Mech. Eng. 191: 1755-1789

Ben-Haim Y, Elishakoff I 1990 Convex models of uncertainty in applied mechanics. Amsterdam: Elsevier

Biondini F, Bontempi F, Malerba G P 2004 Fuzzy reliability analysis of concrete structures. Computers and Structures 82(13): 1033-1052

Bratina S, Saje M, Planinc I 2004 On materially and geometrically nonlinear analysis of reinforced concrete planar frames. Int. J. of Solids and Struct. 41: 7181-7207

Cakiroglu A 1962 Buckling analysis of multi-storey frames. In: Proc. of technical conference of Turkish Civil Engineers (in Turkish)

CEB-FIB 1993 Model Code. Bull. D’information CEB, 213/214, Lausanne

Cheong-Siat-Moy F 1999 An improved K-factor formula. J. Struct. Eng. 125(2): 169-74

Demir F 2005 A new way prediction of modulus of elasticity of normal and high strength concrete-fuzzy logic. Cement and Concrete Research 35(8): 1531-1538

Demir F, Korkmaz K A 2008 Prediction of lower and upper bounds of elastic modulus of high strength concrete. Construction and Building Material 22: 1385-1393

Elishakoff I 1999 Whys and hows in uncertainty modeling, probability, fuzziness and anti-optimization. New York: Springer-Verlag, Wien 
Faison H, Comartin C D, Elwood K 2004 Reinforced concrete moment frame building without seismic details. Earthquake Engineering Research Institute (EERI) and International Association for Earthquake Engineering (IAEE) Housing Report 111.

GBJ11-89 1994 Chinese Design Code, National standard of the People's Republic of China, Chinese code for seismic design of buildings. Beijing: NewWorld Press

GDC 2000 Greek Design Code, Greek National Code Center, Athens, Greece

Gesoglu M, Guneyisi E, Ozturan T 2002, Effects of end conditions on compressive strength and static elastic modulus of very high strength concrete. Cement and Concrete Research 32(10): 1545-1550

Girgin K, Ozmen G 2007 Simplified procedure for determining buckling loads of three-dimensional framed structures. Eng. Struct. 29(9): 2344-2352

Girgin K, Ozmen G, Orakdogen E 2006 Buckling lengths of irregular frame columns. J. Constructional Steel Research 62(6): 605-613

IDC 2003 Italian Design Code, IDC3274, Come Modificato Dall'OPCM 3431. Italy: Public and Health Ministry

Ke-Ru W, Bing C, Wu Y, Dong Z 2001 Effect of coarse aggregate type on mechanical properties of highperformance concrete. Cement and Concrete Research 31(10): 1421-1425

Kim Y M, Kim C K, Hong S G 2006 Fuzzy based state assessment for reinforced concrete building structures. Eng. Struct. 28(9): 1286-1297

Korkmaz K A, Demir F, Tekeli H 2008 Elastic modulus effects of concrete on buckling of R/C Buildings. 12th International Conference on Computing in Civil and Building Engineering, October 16-18, Beijing, China

Korkmaz K A, Tekeli H, Demir F 2009 Determination of elastic moduli effects on storey-drifts by fuzzy logic algorithm. Civil Engineering and Environmental Systems 26: 249-262

Kosko B 1992 Neural networks and fuzzy systems. Englewood Cliffs (NJ): Prentice Hall

LeMessurier W J 1977 A practical method of second-order analysis, 2: Rigid frames. Eng. J. AISC 14(2): 49-67

Lui E M 1992 A novel approach for K factor determination. Engineering Journal, AISC 29(4): 150-159

Mata P, Barbat A H, Oller S, Boroschek R 2008 Constitutive and geometric nonlinear models for the seismic analysis of RC structures with energy dissipators. Architectural Computational Methods Engineering 15: 489-539

Moller B, Beer M 2004 Fuzzy randomness: Uncertainty in civil engineering and computational mechanics. NY: Springer

Moller B, Graf W, Beer M 2003 Safety assessment of structures in view of fuzzy randomness. Computers and Structures 81(15): $1567-1582$

Noor A K, Starnes J R, Peters J M 2001 Uncertainty analysis of stiffened composite panels. Composite Structures 51: 139-158

N S 1992 Norwegian Council for Building Standardization. Concrete Structures Design Rules NS 3473 E, Stockholm, Norway

Ozmen G, Girgin K 2005 Buckling lengths of unbraced multi-storey frame columns. Struct. Eng. and Mech. 19(1): 55-71

Pantelides C P, Booth B C 1999 Computer-aided design of optimal structures with uncertainty. Computers and Structures 74(3): 293-307

Petryna Y S, Kratzig W B 2005 Computational framework for long-term reliability analysis of RC structures. Comput. Methods Appl. Mech. Eng. 194: 1619-1639

Petryna Y S, Pfanner D, Stangenberg F, Kratzig W B 2002 Reliability of reinforced concrete structures under fatigue. Reliability Engineering and System Safety 77: 253-261

Puklicky L, Kala Z 2009 Application of uncertainty analysis to stability problems of steel-concrete structural members. Eng. Struct. and Technol. 1(1): 44-49

Shannag M J 2002 High strength concrete containing natural pozzolan and silica fume. Cement and Concrete Composites 22: 399-402

Stevens L K 1967 Elastic stability of practical multi-storey frames. Proceedings of the Institute of Civil Engineers 36: 99-117 
TDC 2007 Turkish Design Code, Turkish Chamber of Civil Engineering, Izmir, Turkey (in Turkish)

TS 5002000 Turkish Standard, Restrictions for Design and Construction of R/C Structures, Ankara, Turkey (in Turkish)

UBC 1997 Uniform Building Code, International Conference of Building Officials. Vol.2, Whittier, CA, USA

Wee T H, Chin M S, Mansur M A 1994 Stress-strain relationship of high-strength concrete in compression. J. Materials in Civil Eng. 8(2): 70-76

Yura J A 1971 Effective length of columns in unbraced frames. Eng. J. AISC 8(2): 37-42 